\title{
Mapeamento da precipitação em uma Região do Nordeste Brasileiro por meio de técnicas geoestatística
}

No nordeste brasileiro, o histórico de secas e a alta variabilidade de precipitações geram prejuízos econômicos expressivos, o que acarreta demanda por estudo climáticos que possam subsidiar ações que minimizem impactos causados por eventos intensos de precipitação pluviométrica. 0 objetivo deste estudo consistiu em investigar a dinâmica espacial da precipitação no estado de Alagoas, o qual se destaca como grande produtor de cana-de-açúcar da região nordeste. Para tanto, foram utilizados os modelos de variogramas: Exponencial, Esférico e Gaussiano, além da técnica de krigagem. A partir de 20 postos pluviométricos, o índice médio ficou acima de $120 \mathrm{~mm}$ para os meses de abril a agosto para um período de cinco anos (2014-2018), além do mais, esses mesmos meses apresentaram um coeficiente de variação superior a $65 \%$, indicando alta variabilidade espacial da variável estudada. A mesorregião que evidencia o maior número de água precipitada é o Leste Alagoano, já o Sertão Alagoano retrata o menor índice de precipitação no decorrer do ano. Por meio do mapa do erro de predição, foi observado que, mesmo o Sertão Alagoano representando uma mesorregião denominada seca, é possível ocorrer um índice alto de precipitação, da mesma forma o Leste Alagoano pode passar por secas, tendo tomando por base o valor acumulado da precipitação anual. As técnicas utilizadas se mostraram úteis para o mapeamento da precipitação pluviométrica e descrição da variável de interesse em seus principais aspectos e dentre os modelos considerados o que melhor se ajustou aos dados foi o Gaussiano.

Palavras-chave: Chuvas; Krigagem; Modelos de variograma; Validação cruzada.

\section{Rainfall mapping in a Region of Northeastern Brazil using geostatistical techniques}

In the northeast of Brazil, the history of droughts and the high variability of rainfall generate significant economic losses, which leads to a demand for climate studies that can subsidize actions that minimize impacts caused by intense rainfall events. The objective of this study was to investigate the spatial dynamics of precipitation in the state of Alagoas, which stands out as a major producer of sugarcane in the northeast region. For that, variogram models were used: Exponential, Spherical and Gaussian, in addition to the kriging technique. From 20 pluviometric stations, the average index was above $120 \mathrm{~mm}$ for the months of April to August for a period of five years (2014-2018), moreover, these same months presented a coefficient of variation greater than $65 \%$, indicating high spatia variability of the studied variable. The mesoregion that shows the highest number of precipitated water is the East Alagoano, while the Sertão Alagoano shows the lowest precipitation rate throughout the year. Through the map of the prediction error, it was observed that, even the Sertão Alagoano representing a mesoregion called drought, it is possible to have a high rate of precipitation, in the same way the East Alagoano can experience droughts, based on the accumulated value annual precipitation. The techniques used proved to be useful for mapping rainfall and describing the variable of interest in its main aspects and among the models considered, the one that best fitted the data was the Gaussian.

Keywords: Rain; Krigagem; Variogram models; Cross validation

Topic: Hidrogeografia

Reviewed anonymously in the process of blind peer.

Isabelly dos Santos Costa iD

Universidade Federal da Grande Dourados, Brasil

http://lattes.cnpq.br/3459548516806936

http://orcid.org/0000-0001-6611-0809

isabellysaanttos@gmail.com

Elias Silva de Medeiros (iD

Universidade Federal da Grande Dourados, Brasil

http://lattes.cnpq.br/5052910988468793

http://orcid.org/0000-0002-9694-4019

eliasmedeiros@ufgd.edu.br

\section{Alessandra Querino da Silva (iv)}

Universidade Federal da Grande Dourados, Brasi

http://lattes.cnpq.br/4157717143791737

http://orcid.org/0000-0002-1702-0169

alessandrasilva@ufgd.edu.br
Received: 29/04/2021

Approved: 30/05/2021

\author{
Carolina Cristina Bicalho Medeiros (iD) \\ Universidade Estadual de Mato Grosso do Sul, Brasil \\ http://lattes.cnpq.br/8630917382186776 \\ http://orcid.org/0000-0002-4832-1909 \\ carolinabicalho@gmail.com \\ Luciano Antonio de Oliveira (iD \\ Universidade Federal da Grande Dourados, Brasil \\ http://lattes.cnpq.br/8144735782657935 \\ http://orcid.org/0000-0001-5054-2623 \\ ucianoantonio@ufgd.edu.br
}

Referencing this:

COSTA, I. S.; MEDEIROS, E. S.; SILVA, A. Q.; MEDEIROS, C. C. B.; OLIVEIRA, L. A.. Mapeamento da precipitação em uma Região do Nordeste Brasileiro por meio de técnicas geoestatística. Revista Ibero Americana de Ciências Ambientais, v.12, n.5, p.761-769, 2021. DOI: http://doi.org/10.6008/CBPC2179-6858.2021.005.0059 


\section{INTRODUÇÃO}

A precipitação é uma variável meteorológica de fundamental importância para estudos climáticos das diversas regiões do Brasil. Há uma grande preocupação de pesquisadores em analisar a dinâmica espacial das chuvas em todo o território brasileiro, em especial, na região do Nordeste do Brasil (NEB), a qual apresenta uma escassez dos recursos hídricos na maioria das suas unidades federativas. Assim, é de fundamental importância o estudo do comportamento espacial da precipitação tanto para o planejamento das atividades urbanas quanto para administração dos recursos hídricos.

Na NEB o volume anual de precipitação é relativamente elevado, comparada com as outras regiões semiáridas, variando entre $400 \mathrm{~mm}$ a $800 \mathrm{~mm}$, porém as concentrações destas chuvas são entre dois a quatro meses, sobre solo cristalino, em sua maior parte, de difícil infiltração, com alto teor de cloreto de sódio, e alta taxa de evaporação. De um modo geral, o controle climático oceânico exerce influência primordial nos níveis pluviométricos da NEB (NÓBREGA et al., 2016). Nesse mesmo estudo também é ressaltado que a variabilidade da precipitação na região é relacionada ao fenômeno El Niño - Oscilação Sul (ENOS) como também é conhecido por ser um dos principais responsáveis pelas variações interanuais da precipitação na NEB.

Vale ressaltar que quando se trata de escassez de chuvas, associa-se logo com a seca do semiárido nordestino, o qual fica localizado na parte central do NEB, região a qual vivencia períodos longos de estiagem, provocado pela irregularidade no regime de chuvas e de sua má distribuição (MARENGO et al., 2016; CORREIA FILHO et al., 2016). Em compensação, quando ocorrem chuvas intensas no NEB, são frequentemente observadas em regiões litorâneas. Quando isso acontece em cidades com infraestrutura precária, que sofrem com falta de saneamento básico e crescimento desordenado, resulta em alagamentos e inundações (FREIRE et al., 2013; ROSENDO et al., 2015; CORREIA FILHO et al., 2016).

Wanderley et al. (2013) destacam em seu estudo que o histórico recorrente de secas de regiões da NEB é responsável por diversos impactos econômicos, afetando negativamente e de forma expressiva a agricultura e pecuária. Assim, o estudo da distribuição das chuvas se torna fundamental para subsidiar ações no sentido de amenizar prejuízos e tentar administrar os inconvenientes causados pelas intempéries da natureza. Técnicas da geoestatística tem se mostrado eficientes no estudo da distribuição da precipitação e podem gerar informações essenciais por meio da krigagem e construção de mapas que descrevem o comportamento de variáveis de interesse (MEDEIROS et al., 2018; MEDEIROS et al., 2019).

O estudo do comportamento espacial de variáveis climáticas é fundamental, em especial a precipitação, tanto para o planejamento das atividades urbanas quanto para administração dos recursos hídricos. A prática habitual tem como base a identificação de regiões homogêneas, padrões individuais ou combinados de diferentes elementos meteorológicos, além de ser desenvolvida por metodologias diferentes, tanto pelo uso de técnicas de análise multivariada e geoestatística (SILVA et al, 2015). Sendo assim, resultados da aplicação de ferramentas de geoestatística podem contribuir para a construção de estratégias e mitigar ações da seca para estados do NEB, como o de Alagoas, que se destaca na produção de cana-de açúcar (WANDERLEY et al., 2013). 
O estado de Alagoas apresenta características similares da dinâmica espacial da precipitação para a maiorias das unidades federativas que compõem a NEB, com altos índice de chuvas no Leste Alagoano, a qual apresenta um clima quente e úmido e escassez de precipitação na mesorregião do Sertão. Compreende-se que a precipitação do Estado está associada a diversos sistemas meteorológicos, dessa maneira a variabilidade da distribuição da precipitação está associada com mudanças que ocorrem nos padrões de circulação atmosférica e com a interação oceano-atmosfera no oceano Pacífico e no Atlântico (CARVALHO et al., 2018). Adicionalmente, a alta variabilidade nas ocorrências das precipitações em Alagoas, são impostos aos fenômenos climáticos, tais como os eventos de ENOS (El Niño - Oscilação Sul), e a influência local e regional da topografia (FERNANDES, 2013; NÓBREGA et al., 2016). Diante disto, o objetivo principal deste trabalho consiste em investigar a dinâmica espacial da precipitação no estado de Alagoas.

\section{METODOLOGIA}

Na Figura 1 é apresentada a distribuição espacial das 20 estações pluviométricas referente ao estado de Alagoas. O Estado de Alagoas está situado à leste da região NEB, fazendo divisa com Pernambuco, ao norte; com Sergipe, ao Sul; com Bahia, ao oeste; e oceano Atlântico, ao leste. Ocupa uma área de aproximadamente $27.768 \mathrm{~km}^{2}$. É formado por 102 municípios e sua capital é Maceió. Usando a classificação de Köppen (SETZER, 1966, ALVARES et al., 2013) como base de estudo, foi concluído que a metade oriental do Estado possui clima do tipo $\mathrm{As}^{\prime}$, o que seria tropical e quente com chuvas de outono a inverno. Porém, a parte Leste Alagoano, próximo à divisa com o Estado de Pernambuco, possui Clima Tropical Úmido. A metade ocidental do Estado, correspondente ao Agreste e Sertão, apresentam condições semiáridas e o Clima Semi-árido quente (BARROS et al., 2012).

De acordo com Silva et al. (2013) existem duas estações durante o ano. A estação seca que tem início em setembro e termina em fevereiro e a chuvosa que começa aproximadamente em março, terminando em agosto. A temperatura no litoral, varia entre 22,5 e $28^{\circ} \mathrm{C}$ não sofrendo grandes oscilações, $\mathrm{e}$ no sertão, varia entre 17 a $33^{\circ} \mathrm{C}$. Os dados de precipitação anual média (mm/ano) utilizados foram obtidos através da Agência Nacional das Águas - ANA (para um período de 5 anos (2014-2018). O Estado de Alagoas está dividido em três microrregiões: Agreste, Leste e Sertão (Fig. 1).

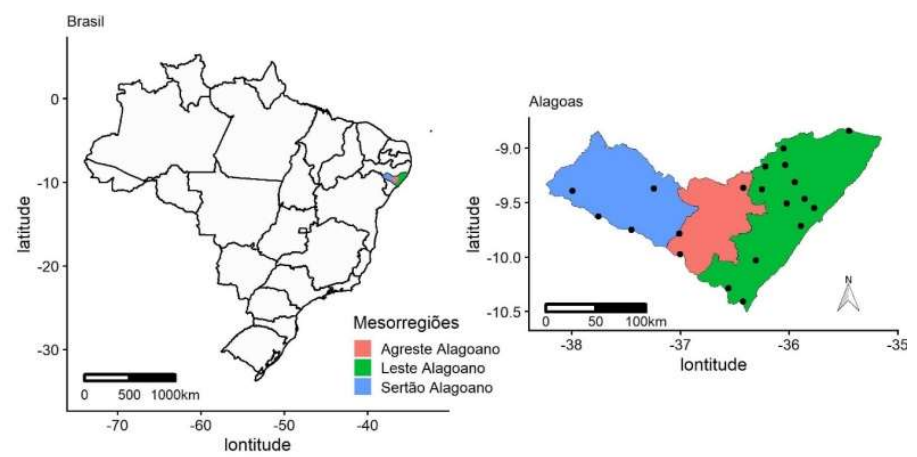

Figura 1: Distribuição espacial das 20 estações pluviométricas (pontos em preto) utilizadas neste estudo para o estado de Alagoas, Brasil.

Para modelar a tendência foram considerados os efeitos das próprias coordenadas geográficas 
(latitude e longitude), considerando polinômios de primeiro e segundo graus. Após removida a tendência foi proposta a obtenção de um variograma empírico e os modelos teóricos exponencial, esférico e gaussiano (Tab. 1) ajustados aos pseudo-dados do variograma empírico.

Tabela 1: Modelos teóricos de variograma com patamar utilizados no ajuste ao semivariograma empírico e o índice de dependência espacial (IDE).

\begin{tabular}{|c|c|c|}
\hline Modelo & Equação & IDE (\%) \\
\hline Esférico & $\begin{array}{c}\gamma(h)=C_{0}+C\left[\frac{3 h}{2 r}-\frac{1}{2}\left(\frac{h}{r}\right)^{3}\right], 0<h \leq r \\
\gamma(h)=C_{0}+C, h>r \\
\gamma(h)=0, h=0\end{array}$ & \\
\hline Exponencial & $\begin{array}{c}\gamma(h)=C_{0}+C\left[1-\exp \left(-\frac{h}{a}\right)\right], h>0 \\
\gamma(h)=0, h=0\end{array}$ & $\frac{C_{0}}{C_{0}+C} \times 100 \%$ \\
\hline Gaussiano & $\begin{array}{c}\gamma(h)=C_{0}+C\left[1-\exp \left(-\frac{h^{2}}{r^{2}}\right)\right], \quad 0<h \leq r \\
\gamma(h)=C_{0}+C, h>r\end{array}$ & \\
\hline
\end{tabular}

Na Tabela (1) $C_{0}$ representa o efeito pepita, $C_{0}+C$ o patamar e $r$ o alcance espacial. No modelo exponencial tem-se a presença de uma assíntota quando o parâmetro $a$ tende a infinito. A função converge para $C_{0}+C$. Assim, em termos práticos, é comum denotar o alcance espacial no modelo exponencial por $r=3 a$. No ajuste dos modelos utilizou-se o método de mínimos quadrados ponderados, sendo os pesos obtidos por $N(h) / h^{2}$, em que $N(h)$ é a quantidade de pontos separados a certa distância $h$.

Após o ajuste dos modelos de variograma, o próximo passo consistiu na krigagem universal para o atributo precipitação seguida de uma validação cruzada "leave-one-out" (MEDEIROS et al., 2019). A validação cruzada foi proposta para seleção do modelo teórico de variograma por meio das estatísticas Raiz-Quadrada do Erro Quadrático Médio (RMSE), Viés Percentual (PBIAS), Nash-Sutcliffe (NSE) e o coeficiente de determinação $\left(R^{2}\right)$.

Tabela 2: Estatísticas utilizadas para seleção do modelo de variograma obtidas pela validação cruzada "leave-one-out" na krigagem universal.

\begin{tabular}{|c|c|c|}
\hline Estatística & Equação & Referência \\
\hline RMSE & $\sqrt{\sum_{i=1}^{n}\left[\frac{\left(y_{i}-\hat{y}_{i}\right)^{2}}{n}\right]}$ & $\begin{array}{l}0 \leq R M S E<\infty \text {. Quanto mais próximo de zero, melhor é o ajuste do modelo } \\
\text { (MORIASI et al., 2007). }\end{array}$ \\
\hline NSE & $1-\sum_{i=1}^{n}\left[\frac{\left(y_{i}-\hat{y}_{i}\right)^{2}}{\left(y_{i}-\bar{y}\right)^{2}}\right]$ & $\begin{array}{l}-\infty<N S E \leq 1 \text {. Valores entre } 0 \text { e } 1 \text { são considerados aceitáveis. Quanto mais } \\
\text { próximo de } 1 \text {, melhor é o desempenho do ajuste (MORIASI et al., 2007). }\end{array}$ \\
\hline PBIAS & $1-\sum_{i=1}^{n}\left[\frac{y_{i}-\hat{y}}{y_{i}}\right] \times 100(\%)$ & $\begin{array}{l}-\infty<P B I A S<+\infty \text {. Quanto mais próximo de zero, melhor é o desempenho do } \\
\text { ajuste. Valores positivos e negativos indicam viés de subestimação e } \\
\text { superestimação do modelo, respectivamente (MORIASI et al., 2007). }\end{array}$ \\
\hline $\mathrm{R}^{2}$ & $\begin{array}{r}\frac{\left[\sum_{i=1}^{n}\left(x_{i}-\bar{x}\right)\left(y_{i}-\bar{y}\right)\right]^{2}}{\sum_{i=1}^{n}\left(x_{i}-\bar{x}\right)^{2} \sum_{i=1}^{n}\left(y_{i}-\bar{y}\right)^{2}} \\
\times 100 \%\end{array}$ & $\begin{array}{l}0 \leq R^{2} \leq 1 \text {. Quanto mais próximo de } 1 \text { (ou 100\%) melhor é o ajuste do modelo } \\
\text { (MORIASI et al., 2007). }\end{array}$ \\
\hline
\end{tabular}

Na Tabela 2 foram apresentadas as expressões e interpretação das estatísticas utilizadas na seleção do modelo teórico de variograma. Os termos $y_{i}, \hat{y}$ e $\underline{y}$ representam o valor observado na $i$-ésima estação pluviométrica $(i=1,2, \ldots 20)$, o valor estimado e o valor médio, respectivamente. Todas as análises estatísticas foram conduzidas no software $R$ (R Core Team, 2019), com apoio das bibliotecas ggplot2 (WICKHAM, 2016) e gstat (PEBESMA, 2004). 


\section{RESULTADOS E DISCUSSÃO}

A Figura 2 apresenta uma análise gráfica da precipitação acumulada mensal do Estado de Alagoas com base no registro dos 20 postos pluviométricos durante os anos de 2014 a 2018. Observa-se que os meses de maio a julho tiveram os maiores índices de precipitação acumulada no período considerado, com valores medianos em torno de $200 \mathrm{~mm}$. Por outro lado, os meses de novembro, dezembro e janeiro foram aqueles com menores índices de precipitação. Notou-se também, a presença de alta variabilidade dentro e entre os meses na região em estudo.

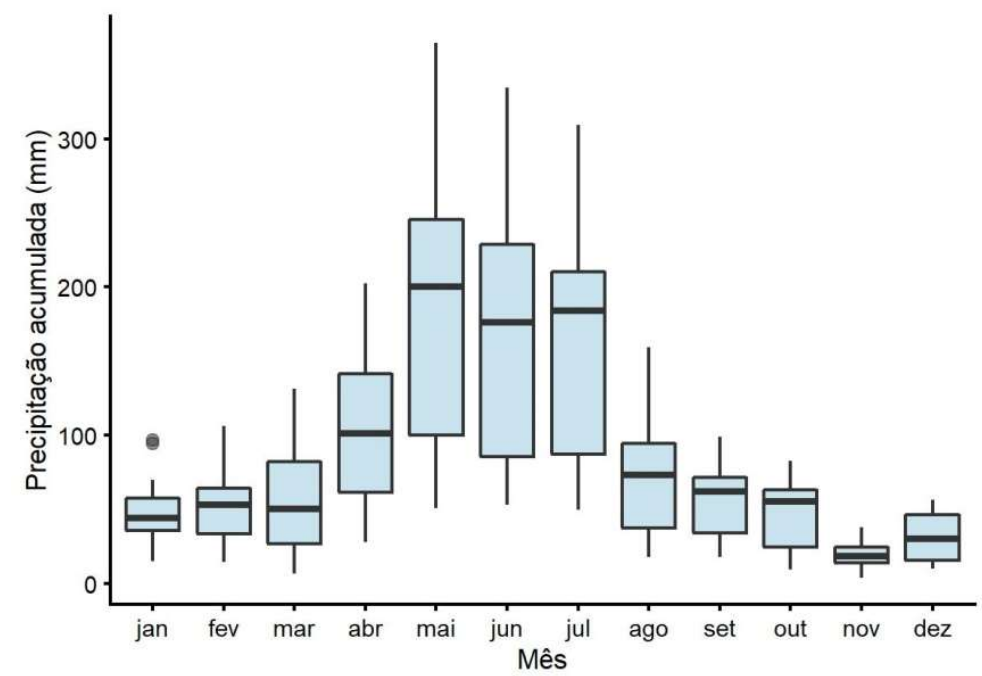

Figura 2: Boxplot da precipitação acumulada mensal com base nas 20 estações pluviométricos analisadas no período de cinco anos (2014-2018) no estado de Alagoas, Brasil.

Resultados similares foram encontrados por Amorim et al. (2008) que, ao estudarem a precipitação pluvial no estado de Alagoas no período de 1963 a 1990 constataram que os meses de novembro, dezembro e janeiro são os mais secos e os meses de maio, junho e julho correspondeu o período mais chuvoso. Adicionalmente, em toda a região do estado de Alagoas, existe irregularidade espacial das chuvas, ocasionando alta variabilidade da precipitação no estado (CARVALHO et al., 2018). Silva et al. (2013) enfatiza esse fato relatando a existência de duas estações no estado de Alagoas com base na periodicidade das chuvas: o período da estação seca, que tem início em setembro e termina em fevereiro, e a chuvosa que começa aproximadamente em março e termina em agosto.

Ainda sobre as irregularidades na distribuição das chuvas, observou-se que a frequência mensal de desastres naturais causados por estiagem e seca no estado de Alagoas, no mês de outubro apresentou a maiores frequências para o período de 23 anos, de 1991 a 2012 (CEPED, 2013). De acordo com esse relatório os municípios mais afetados por estiagem e seca foram Senador Rui Palmeira e Major Isidoro, os quais estão localizados na mesorregião do Sertão Alagoano. No que se refere a precipitação acumulada anual (Fig. 3), nota-se que a longitude apresenta, aparentemente, um efeito quadrático. Observa-se ainda que a variável precipitação não apresenta uma tendência (crescente ou decrescente), em função da coordenada geográfica latitude. 

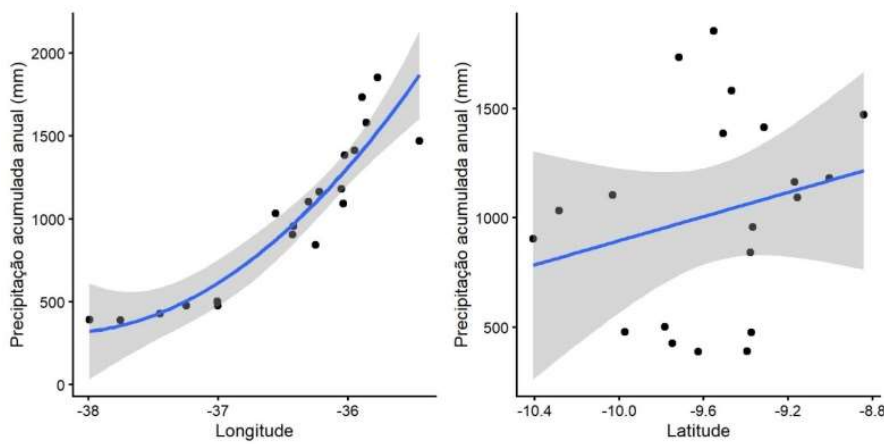

Figura 3: Análise da tendência da precipitação acumulada anual em função das coordenadas geográficas longitude e latitude nos 20 postos pluviométricos.

Assim, foi proposta a construção de diversos modelos para tendência, sendo selecionado o modelo de regressão com intercepto e o efeito quadrático da longitude (Tab. 3). A modelagem do componente de tendência é de fundamental importância para o desempenho da interpolação espacial, uma vez que este componente é responsável pela variação em larga escala do atributo em estudo. Medeiros et al. (2018) ao estudarem o comportamento das chuvas mensais, no período de 1994 a 2011, no estado da Paraíba em 253 postos pluviométricos, também constataram uma tendência quadrática da precipitação em função da longitude. Wanderley et al. (2013) analisaram a distribuição espacial do total acumulado da precipitação no estado de Alagoas, no período entre 1965 a 1980, mas não fizeram o estudo da modelagem da tendência da precipitação em função das coordenadas geográficas. Neste sentido, o trabalho aqui apresentado oferece mais informações.

Tabela 3: Estimativas do modelo de regressão para modelagem da tendência da precipitação acumulada anual.

\begin{tabular}{l|l|l|l|l|l}
\hline Variável & Estimativa & Erro Padrão & Valor t & Valor $\mathbf{p}$ & $\mathbf{R}^{\mathbf{2}}$ \\
\hline Intercepto & -1216 & 239,7 & $-5,074$ & $<0,0001$ & $83,3 \%$ \\
\hline Longitude $^{2}$ & 0,003674 & 0,0003874 & 9,484 & $<0,0001$ & \\
\hline
\end{tabular}

Na Tabela (3) tem-se que o efeito quadrático da longitude é estatisticamente significativo $(P<$ 0,01). Para construção do modelo utilizou-se o efeito da longitude, com unidade de medida em quilômetros. Assim, as chuvas no estado de Alagoas apresentam uma diminuição na direção Leste-Oeste, em que os maiores índices se encontram na mesorregião Leste e que existe uma tendência polinomial de segunda ordem decrescente em direção ao Sertão Alagoano. O valor do coeficiente de determinação $\left(R^{2}\right)$ de $83,3 \%$ sugere que a maior parte da variabilidade espacial da precipitação acumulada na região em estudo é devida ao efeito de tendência. Para investigar a dependência espacial, foi construído o variograma empírico seguido dos ajustes dos modelos teóricos: Esférico, Exponencial e Gaussiano.

Na Tabela 4 são apresentados os resultados da validação cruzada "leave-one-out" com base na krigagem universal para ajustes dos diferentes modelos teóricos de variograma. Adicionalmente, na Figura (4) tem-se o variograma empírico e as linhas de ajuste dos modelos de variograma teórico.

Tabela 4: Resultados da validação cruzada "leave-one-out" para krigagem universal utilizando os modelos teóricos Esférico, Exponencial e Gaussiano.

\begin{tabular}{c|c|c|c|c}
\hline Modelo & RMSE & PBIAS & NSE & $\mathbf{R}^{\mathbf{2}}$ \\
\hline Esférico & 200,69 & $2,60 \%$ & 0,80 & $84,1 \%$ \\
\hline Exponencial & 196,10 & $2,40 \%$ & 0,81 & $84,4 \%$ \\
\hline Gaussiano & 187,91 & $2,30 \%$ & 0,83 & $85,6 \%$ \\
\hline
\end{tabular}


Nota-se na Tabela 4 que o modelo Gaussiano foi o que apresentou os melhores resultados na validação cruzada, sendo este o escolhido para criação dos mapas de interpolação da precipitação acumulada anual no estado de Alagoas.

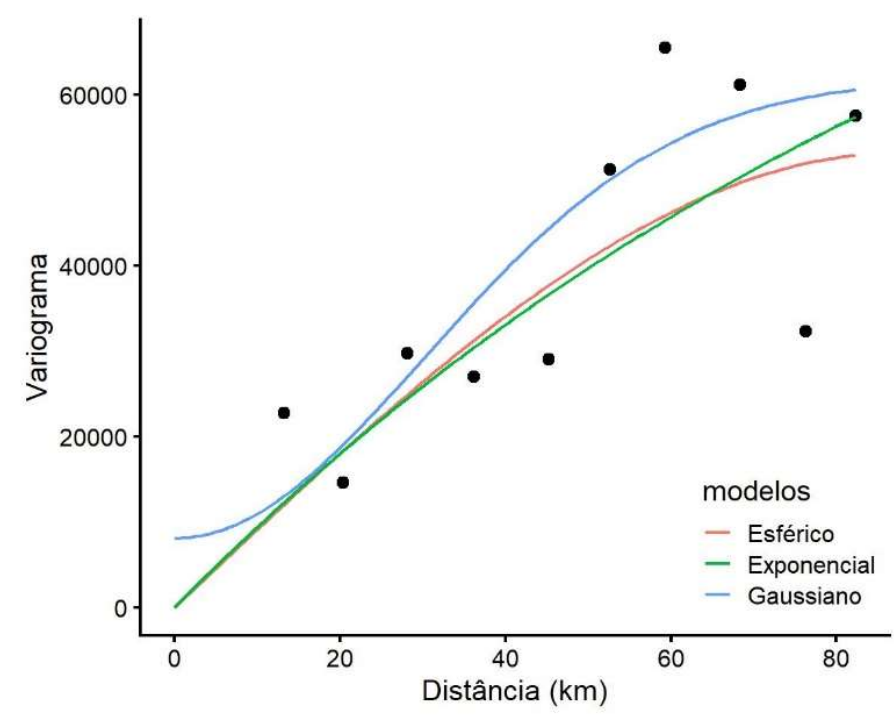

Figura 4: Variograma empírico (pontos pretos) e as linhas de ajuste dos modelos de variograma Esférico, Exponencial e Gaussiano.

As estimativas do modelo Gaussiano são dadas por:

$$
\hat{\gamma}(h)=8112,583+53781,227\left[1-\exp \left(-\frac{h^{2}}{42,788^{2}}\right)\right] .
$$

O alcance espacial no modelo Gaussiano foi de $43 \mathrm{~km}$, sugerindo que locais separados por distâncias maiores que este limiar apresenta baixa dependência espacial entre si. De acordo com as estimativas deste modelo o índice de dependência espacial (IDE) foi de $13,11 \%$, sendo considerada a existência de uma forte dependência (IDE < 25\%) (CAMBARDELLA et al., 1994) da precipitação acumulada anual no estado de Alagoas. Wanderley et al. (2013) ao modelar a distribuição espacial das chuvas no estado de Alagoas, evidenciaram que o ajuste do modelo Gaussiano resultou num índice de dependência de 6,15\%, mas concluíram que o modelo Esférico apresentou melhores métricas, com um IDE de 0,66\%. Na Figura 5 são apresentados os mapas de interpolação e do erro de predição da precipitação acumulada anual $(\mathrm{mm})$ no estado de Alagoas.
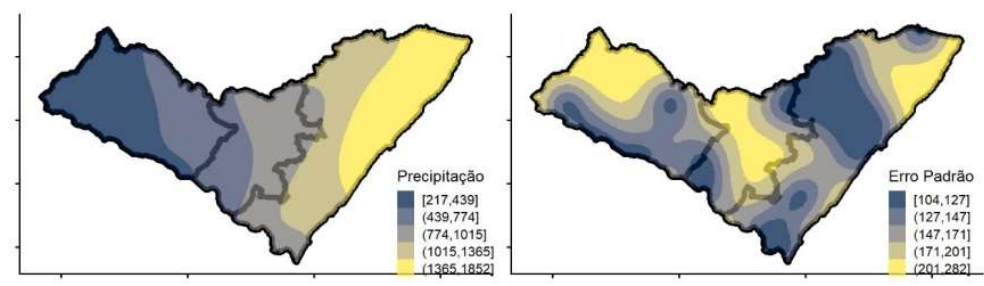

Figura 5: Krigagem (lado esquerdo) e o mapa do erro de predição (lado direito) da precipitação acumulada anual (mm) no estado de Alagoas considerando os registros de 2014 a 2018.

Conforme estimativas do mapa de interpolação, nota-se uma alta variabilidade espacial na direção Leste-Oeste, sendo os maiores níveis da precipitação acumulada anual ocorrem no Leste Alagoano e que 
estes níveis decrescem em direção ao oeste, apresentando menores valores no Sertão Alagoano. Em conformidade com estes resultados, Wanderley et al. (2013) registraram que a mesorregião Leste Alagoano, apresentou níveis de precipitação de até $2000 \mathrm{~mm}$ por ano, e altos níveis são influenciados, diretamente, pelo fluxo de umidade originário do oceano Atlântico sobre o Litoral e a Zona da Mata Alagoana. Os autores supracitados verificaram que dentro da mesorregião do Agreste Alagoano, os índices pluviométricos foram superiores a $1.000 \mathrm{~mm} / \mathrm{ano}$ ao leste desta mesorregião, e inferiores a oeste da região, com precipitação de até 500 mm/ano.

No mapa de erro de predição (Fig. 5, lado direito) a mesorregião do Sertão Alagoano apresenta locais com níveis elevados destes erros, sendo o mesmo observado em locais próximos ao litoral no Leste Alagoano. A baixa disponibilidade de estações pluviométricas no estado de Alagoas e, principalmente, a alta variabilidade das chuvas influenciam os resultados dos erros padrões e isto impacta na adequabilidade das estimativas do atributo em investigação. Diante disto, a grande fragilidade desta pesquisa consiste na disponibilidade de uma baixa quantidade de estações pluviométricas na análise geoestatística. Porém, uma justificativa é que a Agência Nacional das Águas, órgão do governo responsável pela gerenciamentos das informações destas estações, dispõe de poucas estações pluviométricas que apresentam todos os registros diários de precipitação para o Estado de Alagoas. Vale ressaltar que essa região tem a disponibilidade de uma maior quantidade de estações, porém a maioria apresenta dados faltantes e a utilização destas estações na análise estatística provocam várias consequências, tais como, uma representação inadequada dos mapas de interpolação, maiores erros padrões das estimativas e problemas nos ajustes dos modelos de variograma. Porém, para trabalhos futuros, uma solução para utilização de uma quantidade maior de estações pluviométricas consiste no emprego de técnicas estatísticas para imputação e posteriormente a utilização destas estações para criação dos mapas da precipitação.

\section{CONCLUSÕES}

A utilização de técnicas de geoestatística apresentou resultado satisfatório no mapeamento da precipitação no Estado de Alagoas e o modelo gaussiano foi o que melhor se ajustou aos dados pluviométricos. Espera-se que os resultados obtidos por meio desta pesquisa possam auxiliar os órgãos responsáveis pelo gerenciamento dos recursos hídricos na tomada de decisão e na prevenção de desastres ambientais causados pelo excesso e também pela escassez das chuvas no estado de Alagoas.

\section{REFERÊNCIAS}

ALVARES, C. A.; STAPE, J. L.; SENTELHAS, P. C.; MORAES GONÇALVES, J. L.; SPAROVEK, G.. Köppen's climate classification map for Brazil. Meteorologische Zeitschrift, v. 22, n.6, p.711-728, 2013. DOI:

https://doi.org/10.1127/0941-2948/2013/0507

AMORIM, R. C. F.; RIBEIRO, A.; LEITE, C. C.; LEAL, B. G.; SILVA, J. B. G.. Avaliação do desempenho de dois métodos de espacialização da precipitação pluvial para o Estado de Alagoas. Acta Scientiarum. Technology, v.30, n.1, p.87-91, 2008.
BARROS, A. H. C.; ARAUJO FILHO, J. C.; SILVA, A. B.; Santiago, G. A. C. F.. Climatologia do estado de Alagoas. Embrapa, 2012.

CAMBARDELLA, C. A.; MOORMAN, T. B.; NOVAK, J. M.; PARKIN, T. B.; KARLEN, D. L.; TURCO, R. F.; KONOPKA, A. E.. Field-scale variability of soil properties in central lowa soils. Soil science society of America journal, v.58, n.5, p.15011511, 1994. DOI: https://doi.org/10.2136/sssaj1994.03615995005800050033 $\underline{x}$ 
CARVALHO, A. L.. Avaliação climatológica das ocorrências de períodos secos e chuvosos no estado de Alagoas. Caderno de Pesquisa, Ciência e Inovação, v.1, n.3, p.40-50, 2018.

CEPED. Centro de Estudos e Pesquisas em Engenharia e Defesa Civil. Atlas brasileiro de desastres naturais 1991 a 2012. Florianópolis: Federal University of Santa Catarina, 2013.

CORREIA FILHO, W. L. F.; LUCIO, P. S.; SPYRIDES, M. H. C. Caracterização dos extremos de precipitação diária no Nordeste do Brasil. Boletim Goiano de Geografia, v.36, n.3, p. 539-554, 2016. DOI:

https://doi.org/10.5216/bgg.v36i3.44557

FERNANDES, R. C.; CARVALHO, A. L.. Espacialização da precipitação pluvial no município de Piranhas, Alagoas. Ciência e Natura, v.35, n.2, p.295-303, 2013. DOI: https://doi.org/10.5902/2179460X12581

FREIRE, F. G. C.; OLIVEIRA, A. M. P.; SOBRINHO, J. E.; BATISTA, R. O.; SANTOS, W. O.; BARRETO, H. B. F.. Estudo das precipitações máximas para o município de Mossoró-RN, Brasil. Revista Brasileira de Agricultura Irrigada, v.6, n.1, p. 3-7, 2013. DOI: http://dx.doi.org/10.7127/rbai.v6n100070

MARENGO, J. A.; TORRES, R. R.; ALVES, L. M.. Drought in Northeast Brazil - past, present, and future. Theoretical and Applied Climatology, p.1-12, 2016. DOI: https://doi.org/10.1007/s10584-008-9470-5

MEDEIROS, E. S.; OLINDA, R. A.. Probability maps for the rainy quarter in the State of Paraíba. Revista Univap, v.25, n. 46, p.19-29, 2018. DOI:

http://dx.doi.org/10.18066/revistaunivap.v24i46.1902

MEDEIROS, E. S.; LIMA, R. R.; OLINDA, R. A.; SANTOS, C. A. C. Modeling Spatiotemporal Rainfall Variability in Paraíba, Brazil. Water, v.11, n.9, p.1843, 2019. DOI: https://doi.org/10.3390/w11091843

MORIASI, D. N.; ARNOLD, J. G.; VAN LIEW, M. W.; BINGNER, R. L.; HARMEL, R. D.; VEITH, T. L.. Model evaluation guidelines for systematic quantification of accuracy in watershed simulations. Transactions of the ASABE, v.50, n. 3, p.885-900, 2007. DOI: https://doi.org/10.13031/2013.23153
NÓBREGA, R. S.; SANTIAGO, G. A. C. F.. Tendências do controle climático oceânico sob a variabilidade temporal da precipitação no Nordeste do Brasil. Revista de Geografía Norte Grande, n.63, p.9-26, 2016. DOI: http://dx.doi.org/10.5380/abclima.v18i0.43657

PEBESMA, E. J.. Multivariable geostatistics in S: the gstat package. Computers \& geosciences, v.30, n.7, p.683-691, 2004. DOI: https://doi.org/10.1016/j.cageo.2004.03.012

R CORE TEAM. R: A language and environment for statistical computing. Vienna: R Foundation for Statistical Computing, 2019.

ROSENDO, E. E. Q.; SOUZA, B. I.; PIRES, A. L.; PEDROSA, L. P. D.; FILGUEIRA, H. J. A.. Extreme rainfall and territorial disorder in the construction of risk: a case study in the Cabaceiras Municipality of Paraíba, Brazil. Cuadernos de Geografía - Revista Colombiana de Geografía, v.24, n.2, p. 189-203, 2015. DOI: http://dx.doi.org/10.15446/rcdg.v24n2.43924

SETZER, J.. Atlas Climático e Ecológico do Estado de São Paulo. Comissão Interestadual da Bacia Paraná-Uruguai, 1966.

SILVA, D. F.; SOUSA, A. B.. Detecção de tendências climáticas no estado de Alagoas. Revista Brasileira de Geografia Física, v.6, n.3, p.442-455, 2013. DOI: https://doi.org/10.26848/rbgf.v6.3.p442-455

SILVA, A. M.; SILVA, R. M. D.; ALMEIDA, C. A. P. D.; CHAVES, J. J. D. S.. Geostatistical modeling of dengue fever and temperature-rainfall variation in João Pessoa, Brazil. Revista Sociedade \& Natureza, v.1982, p.157-169, 2015. DOI: https://doi.org/10.1590/1982-451320150111

WANDERLEY, H. S.; AMORIM, R. F. C.; CARVALHO, F. O.. Interpolação espacial da precipitação no Estado de Alagoas utilizando técnicas geoestatística. Campo Digital, v.8, n.1, 2013.

WICKHAM, H.. Ggplot2: elegant graphics for data analysis. Springer, 2016. DOI: https://doi.org/10.1007/978-0-387$\underline{98141-3}$

A CBPC - Companhia Brasileira de Produção Científica (CNPJ: 11.221.422/0001-03) detém os direitos materiais desta publicação. Os direitos referem-se à publicação do trabalho em qualquer parte do mundo, incluindo os direitos às renovações, expansões e disseminações da contribuição, bem como outros direitos subsidiários. Todos os trabalhos publicados eletronicamente poderão posteriormente ser publicados em coletâneas impressas sob coordenação da Sustenere Publishing, da Companhia Brasileira de Produção Científica e seus parceiros autorizados. Os (as) autores (as) preservam os direitos autorais, mas não têm permissão para a publicação da contribuição em outro meio, impresso ou digital, em português ou em tradução. 